\title{
Fiber Optics Solutions for Short Pulse Lasers
}

R. Beach, J. Dawson, Z. Líao, I. Jovanovic, B. Wattellier, S. Payne, C.P.J. Barty

January 29, 2003

U.S. Department of Energy

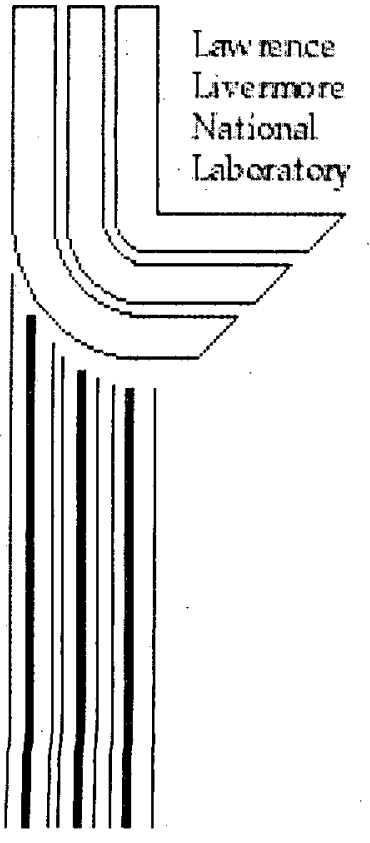




\section{DISCLAIMER}

This document was prepared as an account of work sponsored by an agency of the United States Government. Neither the United States Government nor the University of California nor any of their employees, makes any warranty, express or implied, or assumes any legal liability or responsibility for the accuracy, completeness, or usefulness of any information, apparatus, product, or process disclosed, or represents that its use would not infringe privately owned rights. Reference herein to any specific commercial product, process, or service by trade name, trademark, manufacturer, or otherwise, does not necessarily constitute or imply its endorsement, recommendation, or favoring by the United States Government or the University of California. The views and opinions of authors expressed herein do not necessarily state or reflect those of the United States Government or the University of California, and shall not be used for advertising or product endorsement purposes.

This work was performed under the auspices of the U. S. Department of Energy by the University of California, Lawrence Livermore National Laboratory under Contract No. W-7405-Eng-48.

This report has been reproduced directly from the best available copy.

Available electronically at http://www.doc.gov/bridge

Available for a processing fee to U.S. Department of Energy

And its contractors in paper from

U.S. Department of Energy

Office of Scientific and Technical Information

P.O. Box 62

Oak Ridge, TN 37831-0062

Telephone: (865) 576-8401

Facsimile: (865) 576-5728

E-mail: reports@adonis.osti.gov

Available for the sale to the public from

U.S. Department of Commerce

National Technical Information Service

5285 Port Royal Road

Springfield, VA 22161

Telephone: (800) 553-6847

Facsimile: (703) 605-6900

E-mail: orders@ntis.fedworld.gov.

Online ordering: http://www.ntis.gov/ordering.htm

OR

Lawrence Livermore National Laboratory

Technical Information Department's Digital Library

http://www.llnl.gov/tid/Library.html 
FY02 LDRD Final Report

Project Title: Fiber Optic Solutions for Short Pulse Lasers.

\section{Principle Investigator: Raymond Beach}

Co-investigators: Jay Dawson, Zhi Liao, Igor Jovanovic, Benoit Wattellier, Steven Payne, Chris P. J. Barty

\section{LDRD Tracking Code: 02-ERD-065}

\section{Introduction}

For applications requiring high beam quality radiation from efficient, compact and rugged sources, diffraction limited fiber lasers are ideal, and to date have been demonstrated at average $\mathrm{CW}$ power levels exceeding $100 \mathrm{~W}$ with near diffraction limited output. For conventional single-core step-index single-mode fibers; this power level represents the scaling limit because of nonlinear and laser damage considerations. Higher average powers would exceed nonlinear process thresholds such as the Raman and stimulated Brillouin scattering limit, or else damage the fiber due to the high intensity level in the fiber's core. The obvious way to increase the average power capability of fibers is to increase the area of their core [1]. Simply expanding the core dimensions of the fiber allows a straightforward power scaling due to enhanced nonlinear and power handling characteristics that scale directly with the core area. Femtosecond, chirped-pulse, fiber lasers with pulse energies greater than $1 \mathrm{~mJ}$ have been demonstrated in the literature [2] using this technique. This output energy was still limited by the onset of stimulated Raman scattering. We have pursued an alternative and complimentary approach which is to reduce the intensity of light propagating in the core by distributing it more evenly across the core area via careful design of the refractive index profile [3].

We have also sought to address the primary issue that results from scaling the core. The enhanced power handling capability comes at the expense of beam quality, as increasing the core diameter in standard step index fibers permits multiple transverse modes to lase simultaneously. Although this problem of multimode operation can be mitigated to some extent by appropriately designing the fiber's waveguide structure, limitations such as bend radius loss, sensitivity to thermally induced perturbations of the waveguide structure, and refractive index control, all become more stringent as the core diameter grows, limiting the extent to which the core diameter can be grown and still ensure single mode operation from the fiber. The large flattened mode fiber addresses some of these limitations and enables a new approach to single transverse mode operation of large mode area (LMA) fibers, providing a route to high average powers exceeding $1 \mathrm{~kW}$ from a single aperture in a Strehl-ratio-optimizing flat-topped output beam. 


\section{Theory}

There are two degrees of freedom in the way modal gain discrimination can be managed in cylindrically symmetric fibers. Both the refractive index profile and the gain profile can be modulated radially to first promote specific modal fields, and then to favor some subset of the total supported mode spectrum of the structure. As an example, Fig. 1 shows a specific refractive index profile and gain profile that supports a flattened-mode. A very low NA structure is utilized to limit the total number of modes that are guided by the fiber.

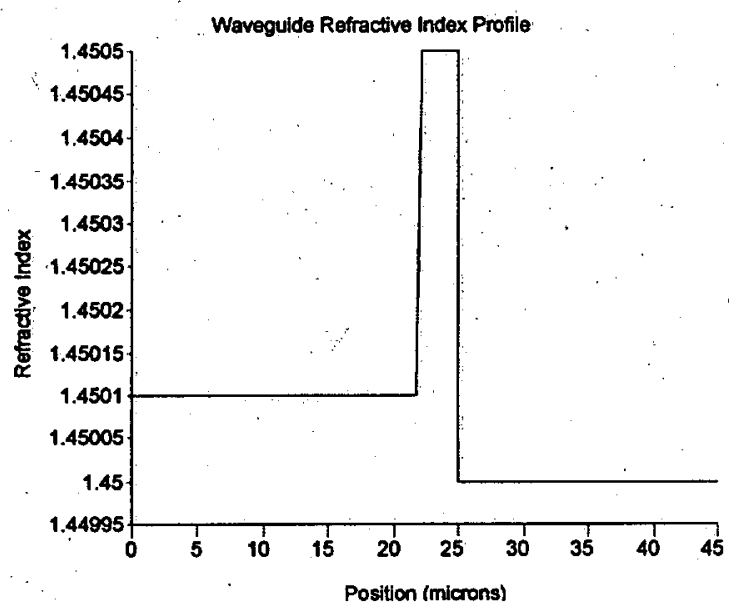

(a)

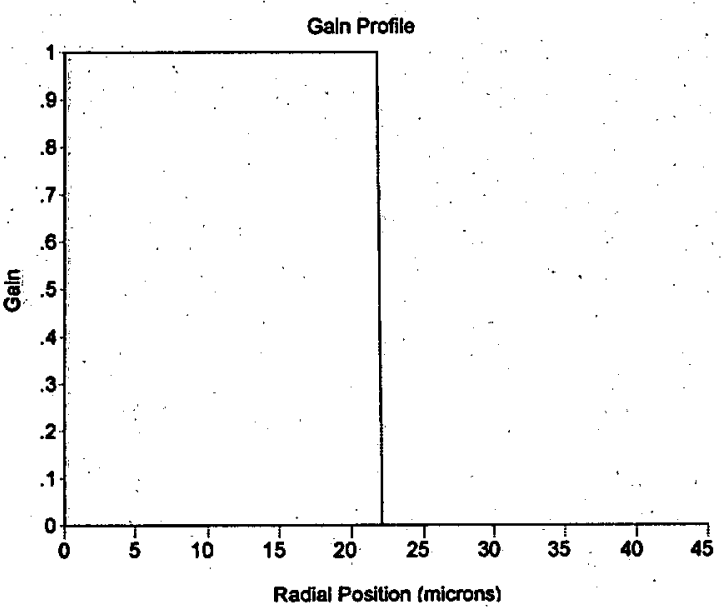

(b)

Fig. 1 (a) Radial refractive index profile of a $50 \mu \mathrm{m}$ diameter cylindrically symmetric fiber. (b) Radial gain profile of fiber ( 0 indicates no gain and 1 indicates gain).

The particular design shown in Fig. 1 corresponds to a $50 \mu \mathrm{m}$ diameter fiber core and uses refractive index values that are conveniently accessible in fused silica. The gain is confined to an interior region having a radial extent of $22.2 \mu \mathrm{m}$, leaving a $2.8 \mu \mathrm{m}$ wide outer undoped annular ring with a refractive index elevated from the outer cladding by $5 \times 10^{-4}$. The specific choice of the index structure shown in Fig. 1a limits the total number of supported transverse modes to only three, and as will be shown, one of these has the desired flat-topped irradiance profile. The gain profile shown in Fig. $1 \mathrm{~b}$ is then designed to strongly favor this preferred flat-topped mode over the other supported modes. Importantly, the fiber design in Fig. 1a uses index step variations of $1 \times 10^{-4}$, which are within the control limits of today's fused silica based fiber preforms from which fibers are pulled.

Figure 2 shows the only allowed $m=0$ eigenmode, where $m$ refers to the azimuthal quantum number of the eigenmode $\left(\mathrm{e}^{\mathrm{i} m \varphi}\right)$, of the optical structure shown in Fig. 1a. 


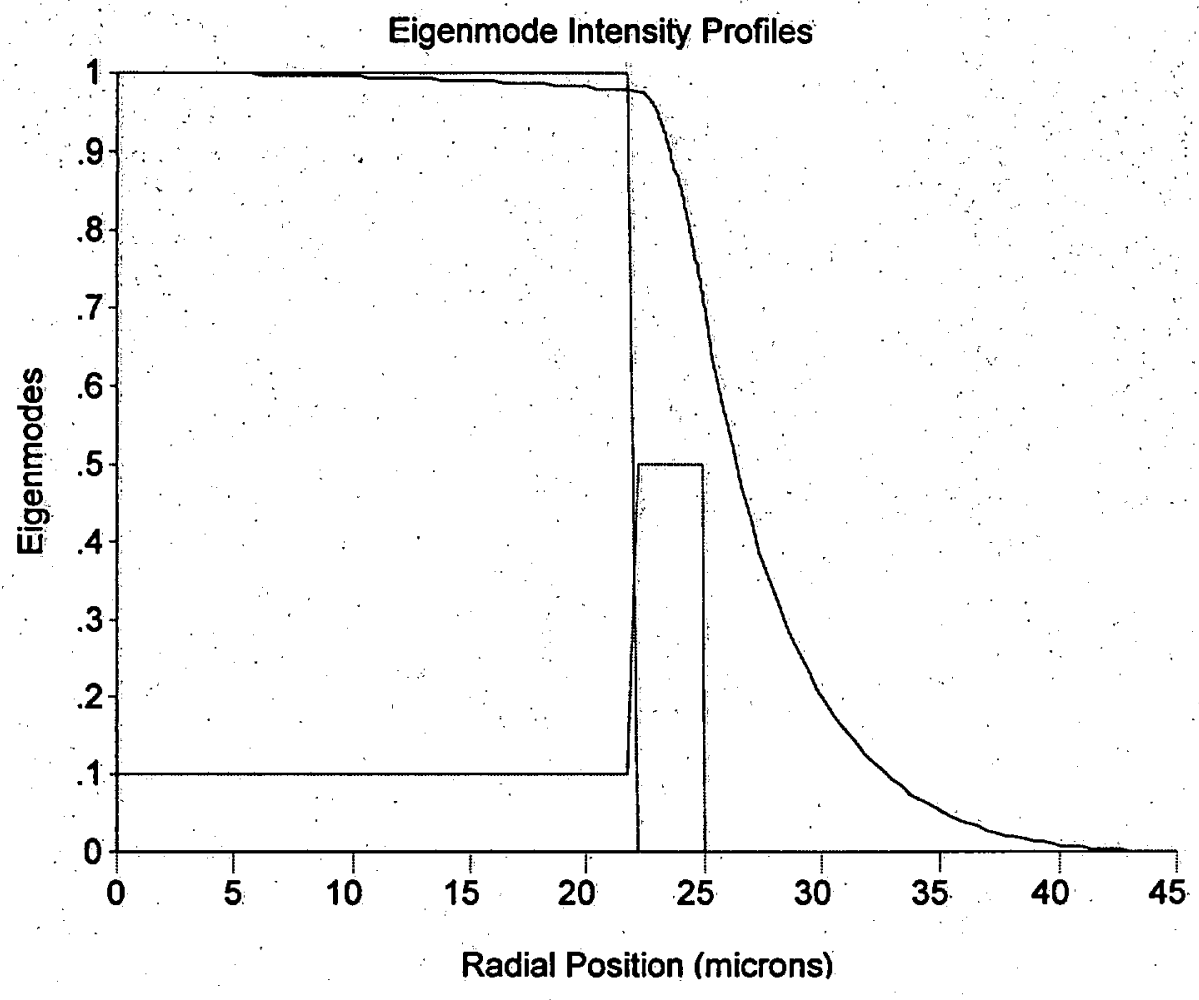

Fig. 2. The only allowed $m=0$ eigenmode of the index modulated structure shown in Fig. 1a. Also indicated in green is the gain and in red the index profile (not to scale).

The elevated index in the annular ring between $22.8 \mu \mathrm{m}$ and $25 \mu \mathrm{m}$ is present to ensure the mode shown in Fig. 2 is confined. Additionally, the width and height of this elevated index ring is chosen to engineer the confined mode in Fig. 2 so as to have a nearly flat irradiance profile within the central portion of the fiber. Because a flat-topped profile is the aperture distribution that gives the highest Strehl ratio, this feature of our fiber design is very important for any application requiring optimized on-axis laser intensity in the far field. Additionally, the flat-topped mode benefits damage considerations, as there are no local regions having peaked irradiance. The effective mean field diameter of the $m=0$ mode in Fig. 2 is $54 \mu \mathrm{m}$ and was chosen to maintain robust single mode behavior in the presence of the thermal gradients that will be set up in the actively pumped structure. This design consideration will be discussed in more detail below.

The gain experienced by different laser modes is proportional to the overlap factor, $\Gamma$, of the mode's intensity envelope with the gain-loaded portion of the fiber,

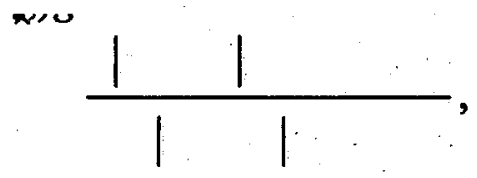

where $g(r)$ is a function with value unity in those portions of the fiber that are gain loaded and 0 where there is no gain loading. This is a straightforward calculation once the 
eigenmode fields are known. In addition to the $\mathrm{m}=0$ eigenmode shown in Fig. 2 , the optical structure shown in Fig. la also supports a single $m=1$ eigenmode and a single $\mathrm{m}=2$ eigenmode, both of which are shown in Fig. 3 .

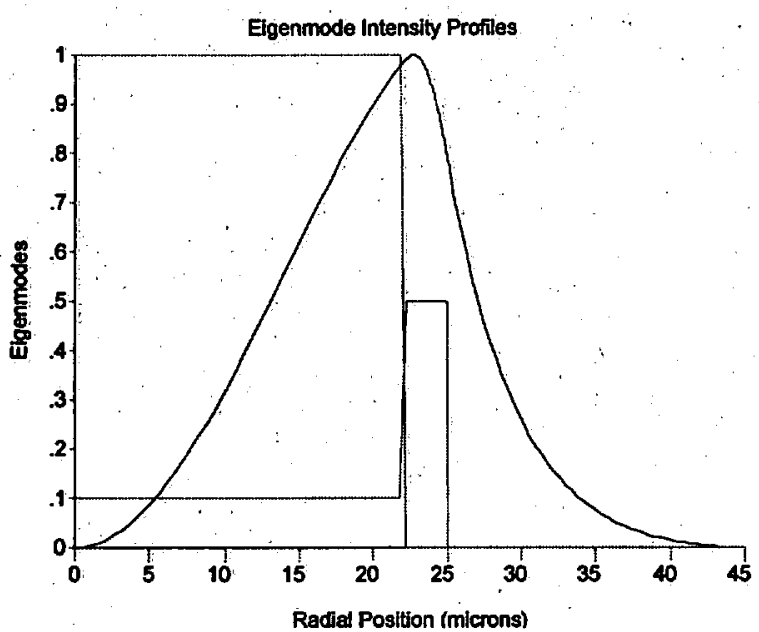

(a)

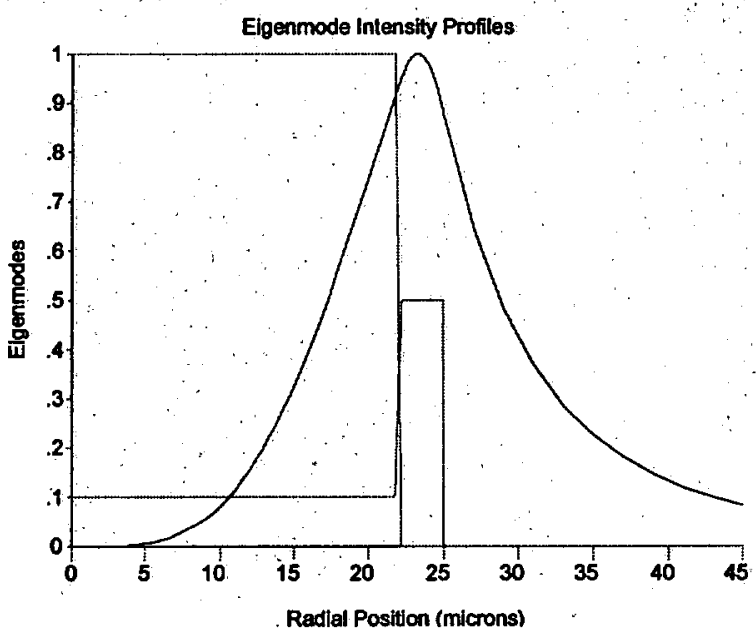

(b)

Fig. 3. (a) The only allowed $m=1$ eigenmode of the fiber structure shown in Fig. 1a. Also indicated in green is the gain profile and in red the index profile (not to scale). (b) The only allowed $m=2$ eigenmode of the fiber structure shown in Fig. 1a.

The eigenmodes depicted in Figs. 2 and 3 are the only allowed eigenmodes supported by the optical structure in Fig. 1a. The eigenmode shown if Fig. 2 fills the aperture and is nearly flat-topped in profile, which means it will have a high Strehl ratio, and for this reason is the mode we want to favor in the operation of the device. Locating the gain along the center of the fiber, coinciding with the index well there, as shown in Fig. 1a, gives a gain discrimination between the allowed modes that favors the flat-topped mode; the overlap of the flat-topped mode shown in Fig. 2 is 0.79 , while that of the modes shown in Fig. 3 is only 0.58 for the $m=1$ mode and 0.33 for the $m=2$ mode.

The same design rationale that went into engineering a cylindrical index profile to ensure it supported a flat-topped mode can also be applied to ribbon structures in the transverse dimension perpendicular to the ribbon-guiding dimension. An example of such a flattopped enabling one transverse dimension index structure is shown in Fig. 4. 


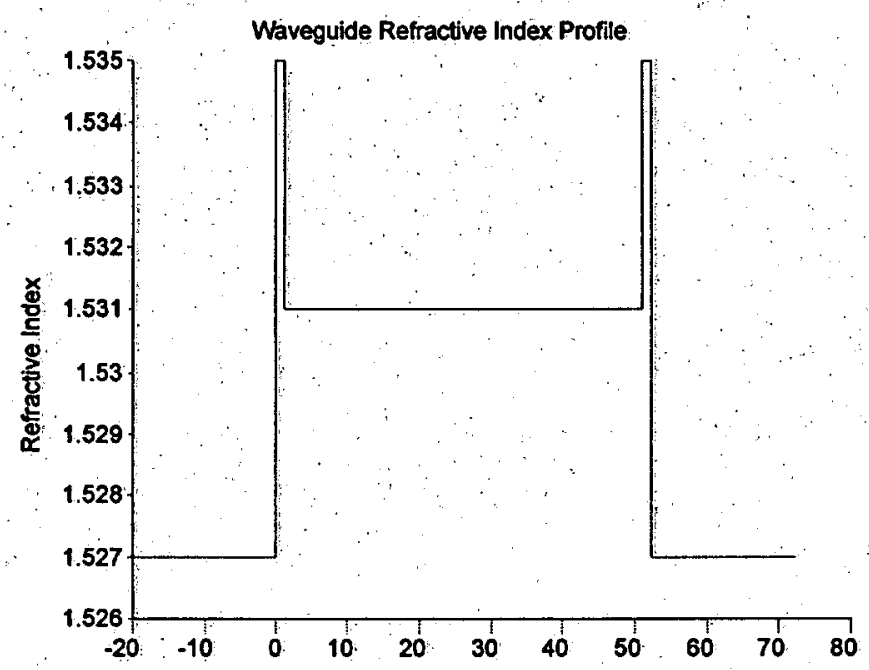

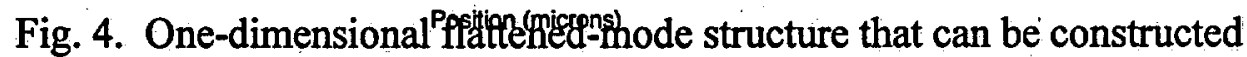
from soft glasses and is compatible with refractive index control at the level of $1 \times 10^{-3}$.

The connection with the two-dimensional cylindrically symmetric shown in Fig. 1 is evident. The elevated index tabs at the edge of the waveguide region are engineered in their height and width to specifically support the flat-topped mode that is depicted in Fig. 5.

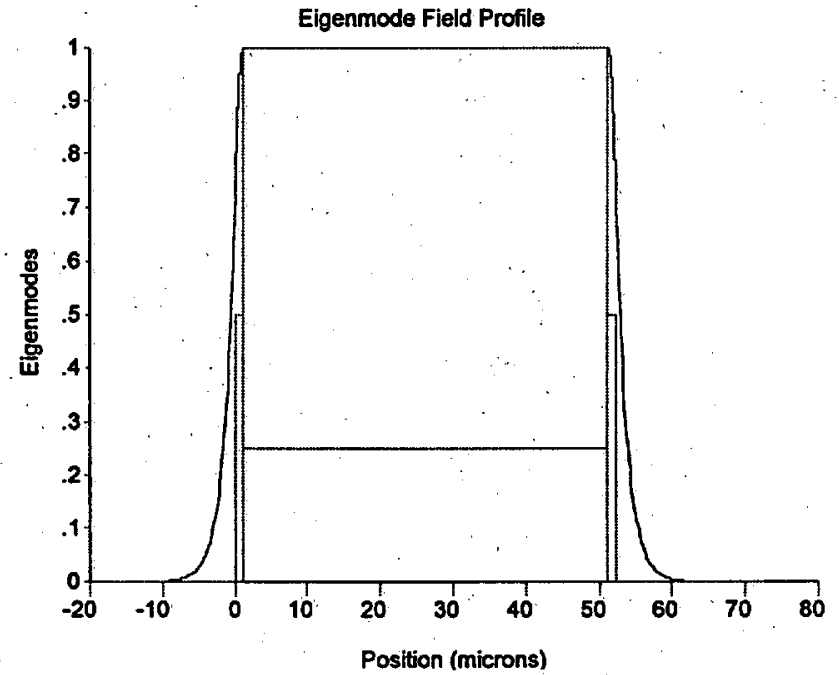

Fig. 5. The one-dimensional waveguide structure of Fig. 4 supports the flat-topped mode shown here. Also indicated in green is the gain profile and in red the index profile (but not to scale). 


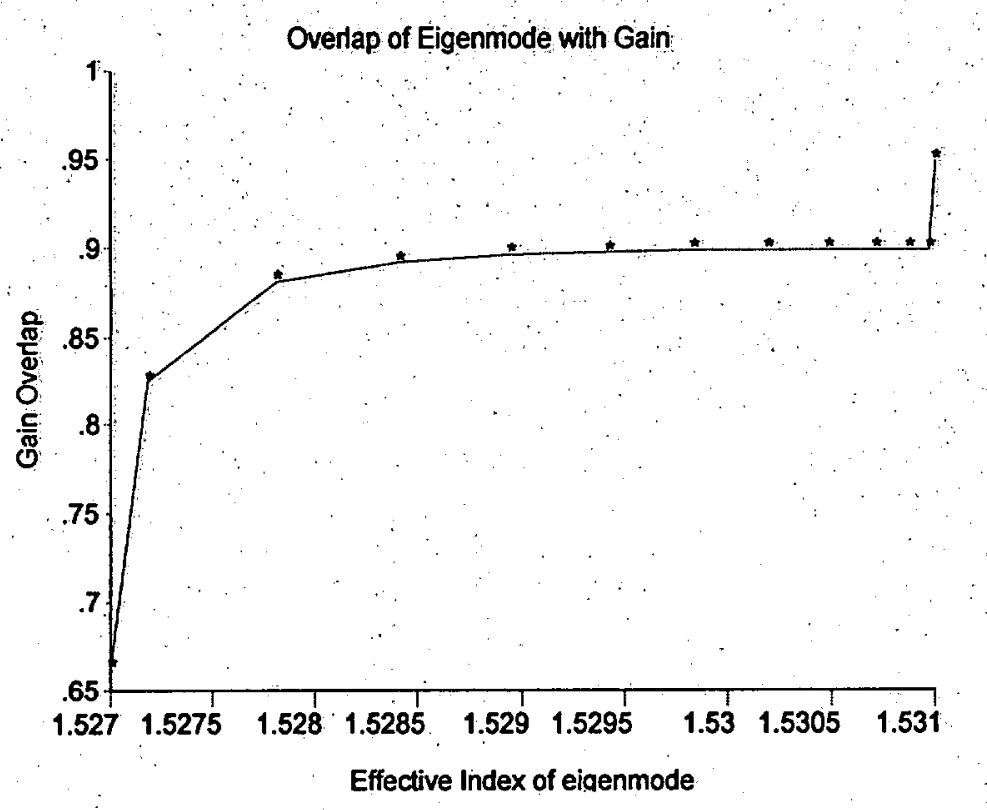

Fig. 6. Calculated overlap of the eigenmodes of the one-dimensional waveguide shown in Fig. 4 with the gain-loaded portion of the waveguide, as a function of the eigenmodes' effective index value.

The graph in Fig. 6 plots the calculated overlap of the eigenmodes supported by the onedimensional waveguide structure of Fig. 4 the gain-loaded portion of the waveguide, the $\Gamma$ factor given by (1), as a function of the eigenmodes' effective index value. This is a straightforward calculation once the eigenmode fields are known. The effective index values, $\mathrm{n}_{\mathrm{eff}}$, associated with the various eigenmodes of the structure is defined by,
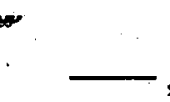

where $\beta$ is the longitudinal wavevector associated with the eigenmode. From (2) it is seen that $\mathrm{c} / \mathrm{n}_{\mathrm{eff}}$ is just the phase velocity associated with the eigenmode as it propagates in the ribbon structure. The two parameters, $\mathrm{n}_{\mathrm{eff}}$ and $\Gamma$, completely define an eigenmode in terms of its wave-optics propagation and energetics behavior. The spectrum of values of $\mathrm{n}_{\text {eff }}$ and $\Gamma$ for a given structure completely defines its modal properties, which can be conveniently summarized in a plot such as Fig. 6 . Examining Fig. 6, the highest effective index eigenmode, which corresponds to the flat-topped mode plotted in Fig. 5, is also the mode with the highest gain overlap. The larger number of eigenmodes supported by the one-dimensional structure of Fig. 4 compared to the cylindrically symmetric fiber structure of Fig. 1 is a result of the larger $\Delta n$ (index variations) used in its design. Even so, the highest gain mode in Fig. 6 has an overlap with the gain region that is discriminated by $5 \%$ from the next highest gain mode, a level that should be sufficient to measure experimentally. Figure 7 illustrates how this approach is applicable to the thin dimension of a ribbon fiber. 


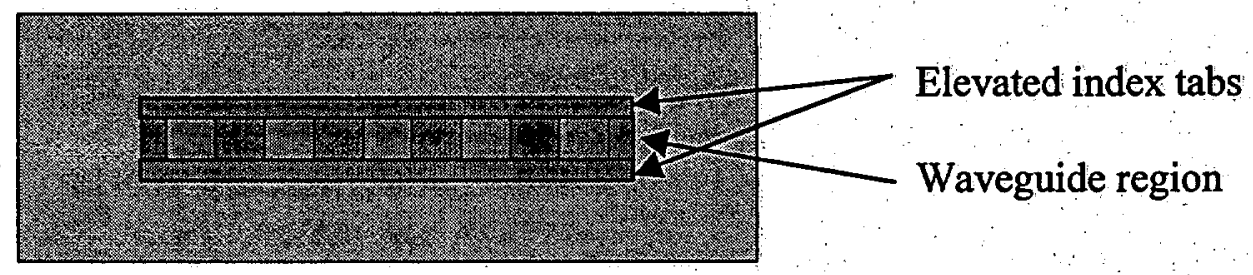

Fig 7. End on view of a ribbon fiber containing elevated index tabs in the strips located at the top and bottom of the waveguide region. These tabs enable the vertical transverse dimension of the waveguide to be increased while still ensuring flat-topped mode operation in that dimension as detailed above.

\section{Experiment}

In figure 8, we show the refractive index profile for the flat-topped fiber mode we obtained for our experiments on the left hand side. On the right hand side of figure 8 , we show the intensity distribution of a large flattened mode fiber design (LFM) and a control standard step index profile fiber of the same core diameter normalized such that the total power contained in the two modes is the same. (i.e. The two intensity distributions contain the same total power after the integration over the full cross sectional area is performed.) We see the LFM design decreases the peak intensity on axis by a factor of 2.46 , which should lead to a significant decrease in the amount of stimulated Raman scattering for a given pulse energy, while not compromising the power handling capability.
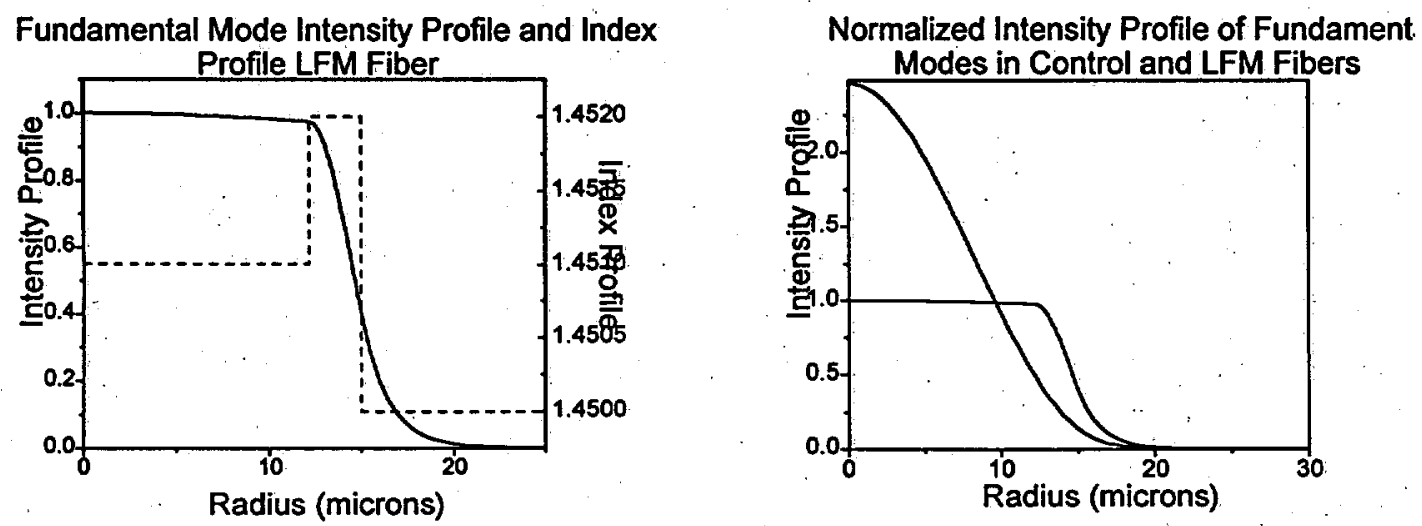

Figure 8: Left: refractive index profile and preferred mode of LFM fiber. Right: comparison of the intensity profiles of a step index fiber and an LFM fiber with the same total power. 
We purchased a $30-\mu \mathrm{m}$ core, $0.06-\mathrm{NA}$, step-index, control fiber (Nufern) with a $400 \mu \mathrm{m}$ hexagonal cladding with a low index polymer coating (pump clad $N A=0.37$ ). The core was doped with $\mathrm{Yb}^{3+}$ such that there was an effective core absorption of $120 \mathrm{~dB} / \mathrm{m}$ at $977 \mathrm{~nm}$. We also purchased a nearly identical fiber from Nufern, but with the raised ring that gives the LFM fiber its distinctive index profile. The inner core diameter of the LFM was $25.3 \mu \mathrm{m}$ and the outer core diameter was about $30-\mu \mathrm{m}$ FWHM, the effective NA of the structure was approximately 0.06 . The outer cladding and $\mathrm{Yb}^{3+}$ doping were the same as for the control fiber.

We then coupled 1.2 -ns, $1075-\mathrm{nm}, 10-\mathrm{Hz}$ stretched mode-locked laser pulses into $9.1 \mathrm{~m}$ of the control fiber and $8: 3 \mathrm{~m}$ of the LFM fiber. The input energy coupled into the fiber cores was $15 \mu \mathrm{J}$. $977 \mathrm{~nm}$ pump light from a $10 \mathrm{~W}$ diode laser array was counter propagated through the fiber to pump the $\mathrm{Yb}^{3+}$ ions. The diode light was pulsed at $10 \mathrm{~Hz}$ for $1 \mathrm{~ms}$ timed to precede the arrival of the signal light. In figure 9 below, we show the amplified output energy of the two fibers on the left hand side measured with a Molectron energy meter. As expected they produce roughly the same output energy as a function of pump diode current. In right hand side however, we plot the percentage of the signal power contained in the first stokes spectra as measured with an Ocean Optics fiber coupled spectrometer. Here we see, the LFM fiber shows significantly less Raman energy build up as a function of diode current than the control fiber. This is in agreement with what we expected from the design. In addition, we achieved greater than $0.6 \mathrm{~mJ}$. output pulses from the LFM amplifier with less than $5 \%$ of the energy in the Raman spectral band by utilizing pulses stretched to 3 ns. With straightforward scaling of $\mathrm{Yb}^{3+}$ doping concentration to reduce the amplifier length, increasing the core size to $50 \mu \mathrm{m}$ and increasing the pump energy an optimized design could yield output pulses with greater than $10 \mathrm{~mJ}$ of energy and virtually no degradation due to stimulated Raman scattering.
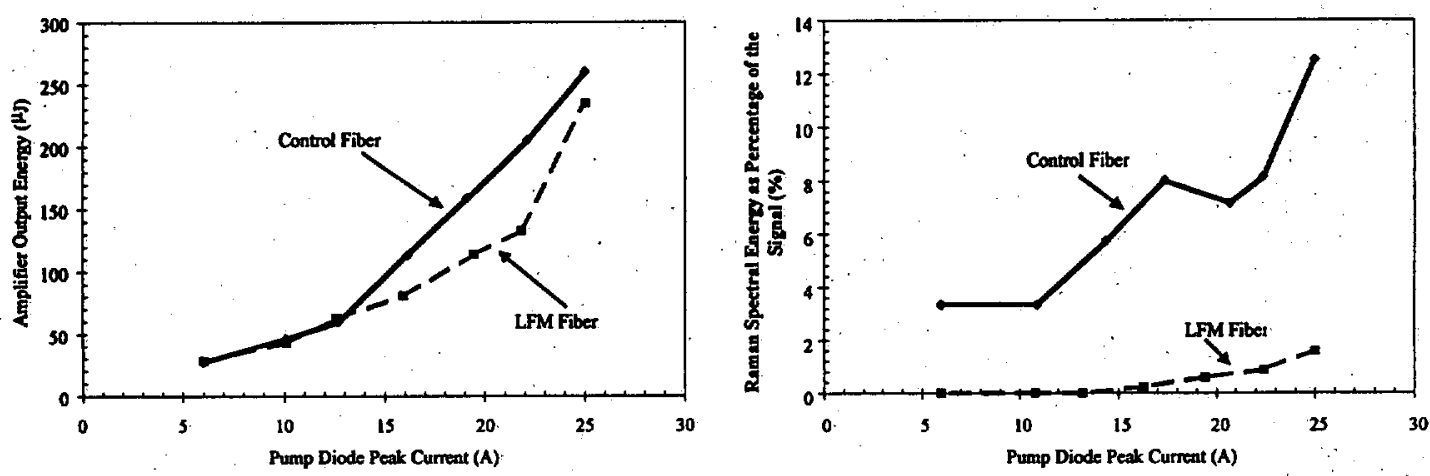

Fig. 9: Left: output energy vs. pump diode current for the step index control fiber and the LFM fiber. Right: Raman peak spectral power as a function of the pump diode current for the same fibers. 


\section{Conclusions}

Our initial investigation of the large flattened mode fiber index profile appears promising. For fibers with similar core sizes, doping concentrations and lengths, we have shown a significant decrease in the amount of Raman scattering in the LFM fiber over a standard step-index fiber. We are in the process of obtaining higher power pump diodes, which will enable us to better quantify the total output energy available from the fiber presently in house. In our next set of investigations, we will also seek to quantify the output beam: quality. Finally, we believe these fibers can be scaled to output energy in excess of $10 \mathrm{~mJ}$ in a straightforward fashion as shown in the table below.

\begin{tabular}{|l|l|l|l|l|l|}
\hline $\begin{array}{l}\text { Pulse } \\
\text { energy }(\mathrm{mJ})\end{array}$ & $\begin{array}{l}\text { Pulse } \\
\text { length } \\
(\mathrm{ns})\end{array}$ & $\begin{array}{l}\text { Core } \\
\text { size } \\
(\mu \mathrm{m})\end{array}$ & $\begin{array}{l}\text { Fiber } \\
\text { length }(\mathrm{m})\end{array}$ & $\begin{array}{l}\text { Fiber gain } \\
(\mathrm{dB})\end{array}$ & Comments \\
\hline 1.2 & 0.4 & 50 & 2.6 & 26 & Galvanauskas, et al. [1] \\
\hline 0.6 & 3 & 30 & 8.3 & 8 & $\begin{array}{l}\text { LFM result from this report. } \\
\text { Higher gains yield increased } \\
\text { output energy before the } \\
\text { onset of Raman scattering. } \\
\text { Our result was hurt by low } \\
\text { gain. }\end{array}$ \\
\hline 9 & 3 & 50 & 2.6 & 26 & $\begin{array}{l}\text { Estimated (assumes one } \\
\text { overcomes Raman scattering } \\
\text { using Galvanauskas system } \\
\text { and increasing pulse stretch } \\
\text { to 3ns) }\end{array}$ \\
\hline 21.6 & 3 & 50 & 2.6 & 26 & $\begin{array}{l}\text { Estimated from above based } \\
\text { on using LFM design to } \\
\text { further increase the Raman } \\
\text { scattering threshold }\end{array}$ \\
\hline
\end{tabular}

\section{References}

1) M.E. Fermann, "Single-mode excitation of multimode fibers with ultrashort pulses", Optics Letters, vol. 23, pp. 52, (1998)

2) A. Galvanauskas, Z. Sartania, M. Bischoff, "Millijoule femtosecond all-fiber system", CLEO 2001, Baltimore, Md., paper CMA1

3) A. K. Ghatak, I. C. Goyal, R. Jindal, "Design of waveguide refractive index profile to obtain flat modal field" SPIE Proceedings vol. 3666, pp. 40 (1998) 